\title{
Factors Influencing the Intention to Donate Blood: The Application of the Theory of Planned Behavior
}

\author{
Nur Zainie Abd Hamid, Rohaida Basiruddin, and Narehan Hassan
}

\begin{abstract}
A question about current availability of the blood has lifted up the concerns on how to keep the world population survive in the future. This has created the necessity to realize the underlying causes rely behind the scenario. The purpose of this study is to investigate the significant application of the Theory of Planned Behavior (TPB) in determining an individual intention and the actual behavior to involve in blood donation specifically in Perlis, Malaysia population. The questionnaire is adapted from prior researches on the application of the TPB. The findings indicated that, the TPB is relevant to the prediction of the intention to donate blood. Besides, among the three factors, Perceived Behavioral Control (PBC) is proved to be the best predictor. As well, the presents of blood donation experience also is said to have influence on an individual's intention since those who ever donated their blood in the past have more intention to donate blood in future than those who are not. The findings from this study are very critical since they can help the authority to improve the current blood donation program and formulate a new strategy to call for more blood donors in the future.
\end{abstract}

Index Terms-Actual behavior, intention to donate blood, theory of planned behavior.

\section{INTRODUCTION}

An increasing demand for more blood has raised the concerned of the society especially those in healthcare setting to beg for more blood donors. In fact, most of the developed countries experienced a critical level of blood shortage since they are unable to meet the demand of blood every day. Argentina, as an example, a country that needs approximately 5,000 donors every day to save about 15,000 lives per day only be able to have 2,600 donors daily [1].

According to World Health Organization (WHO), the statistic of blood collection per year for most of the developing countries showed that, the countries only capable to collect for about $45 \%$ of blood product annually [2]. Even though there is much effort done to boost the participation of the society to involve in blood donation, but, still the amount of blood is not under a required level. This scenario involves a life-threatening issue especially among those who need the blood [3] such as those incurred in injury as well as cancer patients. If this is not addressed properly, it may affect not only a country but the whole world population.

Manuscript received March 21, 2013; revised May 21, 2013

Nur Zainie Abd Hamid and Narehan Hassan are with the Faculty of Business Management, Universiti Teknologi MARA, 42300 Puncak Alam, Selangor, Malaysia (e-mail: nurzainie60@puncakalam.uitm.edu.my, drnarehan.puncakalam.uitm.edu.my).

Rohaida Basiruddin is with the International Business School, Universiti Teknologi Malaysia, 54100 Kuala Lumpur, Malaysia (e mail: rohaida@ic.utm.my).
As in Malaysia, the Malaysian National Blood Centre recognized that, almost all states facing the difficulty to beg for blood donors. The problem is getting worse especially during the festive season [4]. Accident victims who are in need of blood are not be able to save since there is a serious blood shortage in the bank. Even though blood donation activities are organized everywhere, yet, a minimal participation is recorded. This is really true in rural areas such as Perlis, the smallest state in Malaysia. This issue has created the need to understand the population and associate factors that can increase their motivation and willingness to be a blood donor, instead of waiting for volunteers.

Thus, in light of the above discussion, this study is critical in order to identify and analyze the possible contributing factors to the intention to donate blood with an endeavor to seek for better blood donation program and promotion.

\section{LITERATURE REVIEW}

\section{A. The Theory of Planned Behavior}

Nowadays, the scenario of blood shortage has been a serious issue throughout the world. Consequently, this has made blood donation as an area under discussion. One of the ideas that best suit the requirement for calling for more blood donors is through the application of the Theory of Planned Behavior (TPB) [5]. Even though it is an extension from the Theory of Reasoned Action [6], however, both have a consistent groundwork where they try to examine the connection between beliefs, attitudes, normative influence, intention and behaviors except for an additional component of Perceived Behavioral Control (PBC) in TPB.

The essence of TPB is that, a person's readiness to perform a specific behavior or known as behavioral intention will likely cause the actual behavior to be performed. As for example, if a person has the willingness to learn in a class, he or she will likely involve in an actual behavior of learning process such as listening to the lecture and participating in the class. According to the theory, the origin of both intention and actual behavior are from individuals personal attitudes, subjective norms. In an attempt to predict an individual intention and actual behavior, TPB spell out three main factors which are an Attitude toward Behavior (ATB), Subjective Norms (SN) and Perceived Behavioral Control (PBC) [6]. Figure 1 implied the TPB framework as proposed by the original developer, Ajzen [7].

Attitude towards Behavior (ATB). The first construct of TPB is the ATB where it is defined as an overall evaluation of one's behavior [5]. The construct indicate the degree of the performance behavior is valued. Usually, ATB is accessed through behavioral belief where it links the interest behavior 
with the expected outcomes. This is because, behavioral belief represents an individual's self-reported outcome evaluation. Therefore, for instance, when a person holding a believe that, smoking will relieve his or her stress, he or she will have the willingness or tendency to perform the behavior of smoking.

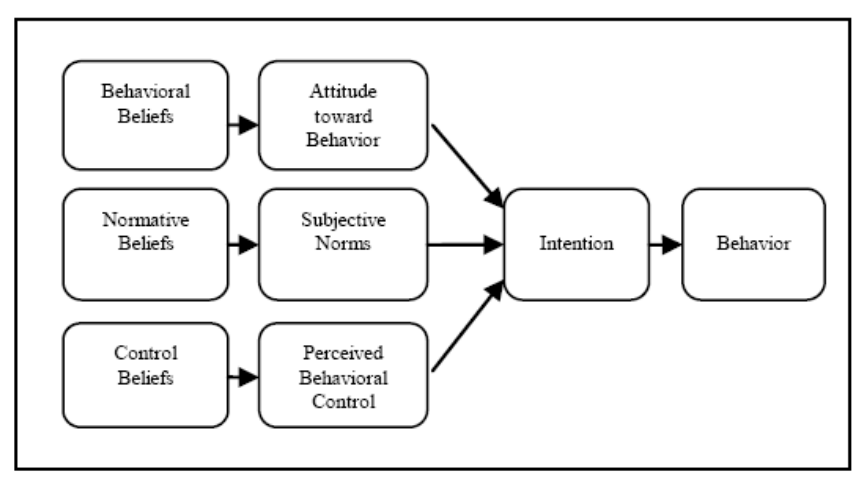

Fig. 1. The theory of planned behavior.

Subjective Norms (SN). By definition, norms are defined as something that reflect the feeling of personal responsibility to perform a behavior [13], in which it implies an individual social pressure or influence to involve in a specific behavior. TPB explained $\mathrm{SN}$ as a construct that determined by normative beliefs which is the expectation that comply with motivation that an individual in common, where a person like to perform something that other person such as their family members, friends, supervisor or the society like to perform since they perceived the behavior is appropriate to perform. This is where, a person will be using information about others' in order to adjust their own behavior and as a result, he or she will perform the same behavior and perceived it as a common behavior in the group.

Perceived Behavioral Control (PBC). $\mathrm{PBC}$ is basically an individual perceptions' of their ability to perform a behavior [7]. It is based on the individual feeling of having control over their own behavior. Usually, PBC will tend to exist when a person estimate the level of difficulty for him or her to perform a specific behavior. This is where the an individual control belief will influence his or her actual behavior. At the time a person had a perceived factor that present in common which may facilitate the performance of the actual behavior, he or she is said to have PBC [8]. This is because, PBC will assist the prediction one's intention to perform since the factors may influence one's decision. As for an example, a person may has a high willingness to donate his or her blood if he or she is confident with his or her ability to survive after the blood transfusion process. While, for those who feel that blood transfusion are not in his or her control, he or she will tend to not engage with the actual behavior. However, sometimes, PBC is often confused with an individual self-efficacy [7]. Self-efficacy is known as people's beliefs about their capabilities to produce a performance that influences events that affecting their lives. This confusion has been cleared by Bandura, whereby, in the study conducted, he provided the distinction between both terms. He concluded that what makes the two terms difference is mainly the words "extent" and "perceived"[9].

Generally, TPB, a well-known theory for a number of disciplines has been adapted in many prior studies and has shown predictive success of the required behavior. Not only in predicting the intention to donate blood, but also the intention of halal food purchasing [9] the usage of technology among students and teachers [10], condom used [11], as well as the mammogram intention [12]. In the field of blood donation, it is examined that, most of the prior studies conducted to test the constructs of the TPB have shown a significant association between the constructs of ATB, SN and PBC with the intention to donate blood. All the TPB components are proving to be relevant and significant in foreseeing the people's intention to perform the behavior [5], [13], [14], [15]. For example, in determining the intention to donate blood, Ben Natan and Gorkov have successfully performed a study among 190 Israeli Jewish aged between 17 to 60 [13]. They found that all the three factors in TPB were good predictors of the intention to donate blood in which the perceived behavioral control was found the best. The study also highlighted the different of behavioral beliefs between those who had donated blood and who had never donated blood whereby those who had never donated their blood have a greater tendency to believe that blood donation and transfusion process is a horrible experience to have. Before hand, worked out by a group led by Godin, they have shown that people who ever donated their blood in live has more power of perceived behavioral control as well as moral norms as compared to those who never donated their blood [15]. Later, this finding also has been successfully supported by a study conducted in Australia by Robinson [14] among 195 residents of Queensland. The thing that differs from the study performed by Ben Natan and Gorkov is that the respondents of this study are randomly self-selected from the total number of 5,466 residents, in which only non-donors response were analyzed. Both studies implied that, people who have a high intention to donate their blood in the future had a strong feeling of commitment to donate their blood and had a high level of perceived behavioral control with regards to the blood donation. Though each study has their own findings, however, majority of the study showed a significant implication of the TPB in their study.

\section{B. Hypotheses Development}

Prior research all over the world has demonstrated that, the TPB was relevant to predict one's intention and behavior, not only in predicting the behavior of blood donation but also in other areas [7]. Tscheulin and Lindenmeier indicated in their study that, all the variables in the TPB; ATB, SN and PBC influenced the prediction of the intention to donate blood [16]. In fact, studies performed a few years later also concluded the same opinion whereby they also revealed and demonstrated the findings that all the components in TPB had a significant association with the intention to conduct a behavior [13], [15]. Since this study has adapted the same framework to another setting in which involved different population and composition, the researchers tend to overlook the significant application of the theory to the population. Therefore, the primary hypothesis for this study was:

Hypothesis 1: The application of Theory of Planned Behavior is statistically significant in this study.

With regards to the best predictor, prior study by Ben 
Natan and Gorkov has proved that, the perceived behavioral control having the greatest association between the three factors listed in the TPB [13]. In fact, a study in a year later also demonstrated that only $\mathrm{PBC}$ had a significant value towards the intention to donate blood among the three variables in the theory [17]. However, it is realized that, there is also a contradictory results found previously indicated that, the best predictor of the intention to donate blood is the subjective norms [18]. The difference is said to be mainly due to the different characteristics of population and sample examined in the study, since this may affect the findings. With regards to this study, since the population involved the general public which is similar to the study conducted by Ben Natan and Gorkov [13], therefore, the following hypothesis was assumed:

Hypothesis 2: Perceived Behavioral Control (PBC) is the best predictor for the intention to donate blood.

Also of interest, ever donor group was reported to have higher intention to donate blood than those who are not [15]. Beforehand, a study done among university students reported that students with blood donation experience demonstrated high awareness and positive intention to donate blood in the future [19]. The consistent finding was then established by a pilot study where, they concluded that, majority of their respondents who donated their blood previously had higher compliance to donate blood than others [5]. Since the findings revealed that knowledge and experience may have an impact on the individual behavior, the following hypothesis 3 was prepared:

Hypothesis 3: Donor group has the higher intention to donate blood than non-donor group.

\section{Methodology}

\section{A. Sample}

A total of 384 respondents who are conveniencely selected from six areas in Perlis, Malaysia were involved in this study. All respondents are approached personally by the researchers within two months in their residential area. All questionnaires were completed and returned. Each eligible respondent was given a minimum of 15 minutes to answer the questionnaire. Those who have a health problem and aged below than 18 years old and above 50 years old were excluded from the study in order to remove the biases.

\section{B. Instrument}

A set of questionnaire was adapted from prior studies [5],[13],[14]. The questionnaire contains 20 items, five (5) were used to collect the respondents' demographic information, twelve (12) items were: three (3) items on the behavioral belief towards the behavior of blood donation (Cronbach's alpha $=0.947)$, three $(3)$ items on a normative belief that influence blood donation (Cronbach's alpha = 0.803 ) and another three (3) items on control belief that an individual has on the action of blood donation (Cronbach's alpha $=0.951)$. The remaining three (3) items were used to assess the overall individuals' intention to donate blood (Cronbach's alpha $=0.914)$. All questions, except for demographic information were weighted by using 4-Likert scale.

\section{Data Analysis}

All data were analyzed through SPSS version 17.0 database software. At the start, descriptive statistics were used to analyze and describe the sample characteristics. Then, Spearman Rank Order Correlation Coefficient statistic was used to examine the association between the the constructs of ATB, SN and PBC with the intention to donate blood. In addition, Mann-Whitney $U$ Test was also performed to compare the intention to donate blood among donor and non-donor group.

\section{FINDINGS AND DISCUSSION}

The study involved individuals that were eligible to the characteristics of the study. It was equally distributed between male and female. Almost $50 \%$ of the respondents were aged between 31 to 40 years old. Approximately $41 \%$ have a minimum education background of diploma. However, only $31.5 \%$ of them have ever donated their blood in the past in which almost $25 \%$ of them claimed that they have donated their blood between two to five times. Among donor group, it was found that, 85 over 121 donors were male provided that there was a gap to donate blood between gender. This indicated that, majority of the blood contributors in the population were male. Therefore, something should be drafted in order to encourage the readiness to involve in blood donation especially among female residents.

In order to examine the significant use of TPB towards the intention to donate blood among the population, the Spearman Correlation Coefficient test was constructed. As anticipated in Table I, ATB, SN and PBC were proved to have a positive and significant high value towards the intention to donate blood with $0.436,0.618$ and 0.625 respectively. The result showed that all the three components of TPB were relevant and reliable to access the intention to donate blood among the population. This is consistent with prior studies being conducted in which it demonstrates that there was a significant association between the construct of the TPB with the intention to donate blood [13],[14],[15]. In fact, the findings have confirmed the reliability and validity of the TPB since there was a significant positive high correlation coefficient among the components of the theory as proposed by the founder of the theory. Since the test declared that all components of the TPB were statistically associated with each others, therefore, the hypothesis 1 was accepted.

TABLE I: THE CORRELATION BETWEEN THE COMPONENTS OF TPB
\begin{tabular}{|l|l|l|l|r|}
\hline & & ATB & SN & PBC \\
\hline \multirow{2}{*}{$\begin{array}{l}\text { INTENT } \\
\text { ION }\end{array}$} & Correlation Coefficient & $.436^{* *}$ & $.618^{* *}$ & $.625^{* *}$ \\
\cline { 2 - 5 } & Sig. (1-tailed) & .000 & .000 & .000 \\
\cline { 2 - 5 } & N & 384 & 384 & 384 \\
\hline \multirow{2}{*}{$* *$ Correlation is significant at the 0.01 level (1-tailed). }
\end{tabular}

As well, the same correlation test also indicated the result for hypothesis 2 of the study. As figured out, PBC is said to have the highest association with the intention to donate blood. In other words, PBC has proven to be the best 
predictor among others TPB components of the population where it is also found by prior studies [14],[15],[18]. This indicates that the intention to donate blood among the population is very much depending on their individual control. If the individual in the population holds a belief that, it will be easy for he or she to donate blood within a given period of time, he or she most probably will engage with the intention and the actual behavior to donate blood in the future. Thus, the hypothesis 2 was then being supported.

Last but not least, the difference between donor and non-donor group intention was derived from Mann-Whitney $\mathrm{U}$ test. 121 responses from each group (donor and non-donor) were selected. As shown in table II, those with blood donation experience have higher intention to donate blood in the future than those who are not with the mean rank for both donor and non-donor group were 171.52 and 71.48 respectively. This implied that, individuals who never involve in blood donation have no or low willingness to donate blood as compared to individuals who ever donated their blood in the past. This finding is consistent with a study conducted in Korea among the university students where it has been found that, an individual who ever donated their blood also was found to have greater intention to donate blood [19]. The same result also is drawn by a study among Israelis in which the study demonstrated that, Israelis with an experience of blood donation have greater intention to donate blood again compared to who never done so [13]. Therefore, as a result, the hypothesis 3 of the study is said to be accepted.

TABLE II: MANN-WHITNEY U TEST OF DIFFERENCE INTENTION BETWEEN DONOR AND NON-DONOR GROUPS

\begin{tabular}{|l|l|c|l|r|}
\hline & $\begin{array}{l}\text { Blood Donation } \\
\text { Experience }\end{array}$ & $\mathrm{N}$ & Mean Rank & Sum of Ranks \\
\hline INTENTION & Yes & 121 & 171.52 & 20754.00 \\
\cline { 2 - 5 } & No & 121 & 71.48 & 8649.00 \\
\cline { 2 - 5 } & TOTAL & 242 & & \\
\hline
\end{tabular}

Note: $\mathrm{U}=1268.0, \mathrm{p}=0.00$

\section{CONCLUSION}

The Theory of Planned Behavior (TPB) that has been applied in this study has proved that the theory can be a good predictor for blood donation intention especially for the population. All the three components in the TPB have shown a very sufficient contribution in predicting the population intention to donate blood. Through out the analysis and findings, this study has come to the conclusion that Perlis, Malaysia population has the following characteristic towards blood donation:

1) The blood donation intention among the population can be predicted through the three construct of Theory of Planned Behavior (TPB) which is the Attitude towards Behavior (ATB), Subjective Norms (SN) and Perceived Behavioral Control (PBC).

2) An individual who has blood donation experience or who ever donated their blood in the past has more intention to donate blood in the future than who are not.

3) The best predictor among the contructs of TPB that can describe the population in the PBC.
The above characteristics are very useful and critical especially for the state authority since they can make use the factors to foster the participation of the population to involve in blood donation activity. This of course will help in minimizing the risk of losing a life because of insufficient blood supply in the bank. Since the study only focuses on a small population in the country, further research is recommended so that, a better result can be obtained. It is a good attempt to study the various ethnicities or composite group in the country instead of focusing on one similarity group since Malaysia is composed of a number of ethnicities with heterogeneous characteristics. To be more effective and reliable, a study of focus group can be applied instead of relying on the survey instrument. Such methodology will be able to identify the direct reaction of the group towards an issue. The respondents will likely involve in volunteer discussion or interview where they will supply the information needed with freedom. Last but not least is the inclusion of open-ended questions. This type of question will permit unlimited number of answer from respondents where they can answers in details and clarify their response.

\section{ACKNOWLEDGMENT}

The authors gratefully thank the contribution of the Dean of Faculty of Business Management, Universiti Teknologi MARA (UiTM), Malaysia and the Dean of International Business School, Universiti Teknologi Malaysia (UTM), Malaysia. As well, the colleagues, friends and families for the guidance and support throughout the completion of this study.

\section{REFERENCES}

[1] S. V. D. Boogaard. (June 2011). More blood. more life: Argentina's hunt for new donors. [Online]. Available: http://www.argentinaindependen.com/currentaffairs/newsfromargenti na/more-blood-more-life-argentinas-hunt-for-new-donors/.

[2] World Health Organization. (June 2012). Blood supply and availibility. [Online].

Available: http://www.who.int/mediocentre/factsheets/fs279/en/.

[3] H. Rosline, S. A. Ahmed, F. S. Al-Joudi, M. Rapiaah, N. N. Naing, and N. A. Adam, "Thalassemia among blood donor at the Hospital Universiti Sains Malaysia," Southeast Asian Journal of Medical Public Health, vol. 37, no. 3, pp. 549-52, 2006.

[4] News Straits Times. (December 2011). Blood donation appeal ahead of $\begin{array}{lll}\text { festivals. } & \text { [Online]. Available: }\end{array}$ http://www.nst.com.my/opinion/letters-to-the-editor/blood-donation-a ppeal-ahead-of-festivals-1.25949.

[5] J. Mehrdad, L. Latiffah, S. H. S. Tajuddin, H. Parichehr, and O. Mohamed, "Development of a questionnaire for assessing factors predicting blood donation among university students: A pilot study," Southeast Asian Journal Trop. Medical Public Health, vol. 41, no. 3, pp. $660-666,2010$.

[6] A. Icek, "The theory of planned behavior," Organizational Behavior and Human Decision Processes, vol. 50, pp. 179-211, 1991.

[7] A. Icek, "Theory of planned behavour: Implications for an email-based physical activity intervention," Psychology of Sport and Exercise Journal, vol. 9 , no. 4, pp. 511-526, 1991.

[8] A. Bandura, "Social cognitive theory of self regulation," Journal of Organizational and Human Decision Processes, vol. 50, pp. 248-287, 1991.

[9] Syed and M. S. Nazura, "Applying the theory of planned behavior in halal food purchasing," International Journal of Commerce and Management, vol. 21, no. 1, pp. 8-20, 2011.

[10] T. Timothy and B. L. Chwee, "Explaining the intention to use technology among student teachers: An application of the theory of planned behavior," Campus-Wide Information System, vol. 27, no. 2, pp. 60-67, 2010 .

[11] C. C. Carmack and R. K. L. Moss, "Examining the theory of planned behavior applied to condom use: The effect-indicator vs. 
causal-indicator model," Journal of Prim. Preview, vol. 30, no. 6, pp. 659-676, 2009

[12] E. L. Tolma, B. M. Reininger, A. Evans, and J. Ureda, "Examining the theory of planned behavior and the constructs of self-efficacy to predict mammography intention," Health Education and Behavior, vol. 33, pp. 233-251, 2006

[13] M. B. Natan and L. Gorkov, "Investigating the factors affecting blood donation among Israelis," International Emergency Nursing, vol. 1, no. 3 , pp. 1-7, 2010.

[14] Robinson, G. M. Natalie, M. W. Barbara, M. H. Katherine, K. Melissa, and D. J. Terry, "Predicting intentions to donate blood among non-donors in Australia: An extended Theory of Planned Behavior," Journal of Transfusion, vol. 48, no. 12. pp. 2559-2567, 2008.

[15] G. Godin, P. Sheeran, M. Conner, M. Germain, D. Blondeau, C. Gagne, D. Beaulieu, and H. Naccache, "Factors explaining the intention to give blood among the general population," Journal of Sanguinis, vol. 89, pp. 140-149, 2005.

[16] D. K. Tscheulin and J. Lindenmeier, "The willingness to donate blood: An empirical analysis of socio-demographic and motivation-related determinants," Health Services Management Research, vol. 18, pp. 165-174, 2005.

[17] J. Holdershaw, P. Gendall, and M. Wright, "Predicting blood donation behavior: Further application of the theory of planned behavior," Journal of Science Marketing, vol. 1, no. 2, pp. 120-132, 2011.

[18] M. Giles, C. McClenahan, E. Cairns, and J. Mallet, "An application of the theory of planned behavior to blood donation: The important of self-efficacy," Journal of Health Education Resource, vol. 19, no. 4, pp 380-391, 2004.

[19] S. Kam, S. A. Kim, Y. S. Kang, K. S. Park, J. H. Son, M. H. Yeh, K. E. Lee, J. G. Kim, and D. H. Song, "Factors affecting blood donation in university students," Korean J Blood Transfusion, vol. 8, no. 2, pp. 113-124, 1997.

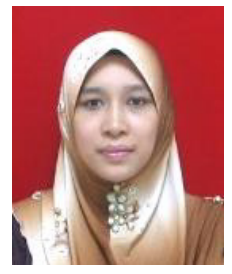

Nur Zainie Abd Hamid was born in Perlis, Malaysia on November 28, 1986. She holds a master degree in MBA Healthcare Management from International Business School (IBS), UTM, Kuala Lumpur in year 2012. Previously, she has worked with Dommal's Food Sdn. Bhd. (Domino's Pizza) as an administrative officer for about one years. Currently, she is working with UiTM, in Puncak Alam Campus, Selangor as a lecturer. She is interested to explore and study the area of huminity, sociality and health. Ms. Nur Zainie has been awarded with schorlarship from UiTM under the Young Lecturer Scheme as well as the Ministry of Higher Education and has received the best student awards for Bachelor Degree in Health Administration (Hons.) program and the best student for Faculty of Office Management and Technology, UiTM, Shah Alam, Malaysia in year 2009.

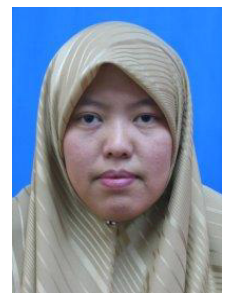

Rohaida Basiruddin was born in Sarawak, Malaysia on August 19, 1978. She holds a Ph.D in Accounting and Financing from Durham University, United Kingdom in year 2011. She has worked as an Account Supervisor at PGEO Edible Oils Sdn. Bhd. In Setiawan, Perak, Malaysia for 2 years, as an Account Executive and Group Office Manager at Azlina Abdul Aziz \& Associates in Ampang, Selangor, Malaysia for two year and as an Account Officer at Eastbourne Corporation Bhd in Selangor Currently, she served as a senior lecturer at IBS, UTM, Kuala Lumpur. She has published a book entitled Corporate Governance, Audit Quality and Opportunistic Earning: An Empirical Analysis of the Relation between Governance Practice, Audit Quality and Earning Management in the UK, LAP Lambert Academic Publishing, ISBN 978-3-8465-1326-2. Dr. Rohaida has been awarded as a member of Golden Key National Honor Society, scholarship from Majlis Amanah Raya MARA for bachelor degree and scholarship from UTM and Ministry of Higher Education for master degree. 